\title{
CONTRABANDISTAS ENTRE TESTIGOS SOSPECHOSOS Y AUTÓMATAS PARLANTES ${ }^{1}$
}

\author{
Mariana Alvarado ${ }^{2}$
}

\begin{abstract}
RESUMEN: A propósito de "el silencio femenino" al que alude Nuria Perez de Lara (2009) para pensar "la construcción de la identidad desde la perspectiva de la diferencia sexual", en la relación entre las mujeres y la producción del conocimiento, en este trabajo se visibiliza el problema creado por el androcentrismo en la historia del pensamiento filosófico latinoamericano de fines del siglo XIX y principios del XX. Se hace eco del protagonismo filosófico de las mujeres en América Latina. A tiempo de proponer perspectivas para pensar otra filosofía, desde la experiencia de ser mujer -de ser una entre unos y otras diferentes a una- que se articule con una política de la mirada femenina que teja una historia de las ideas femeninas latinoamericanas capaz de parir éticas de la alteridad y pedagogías de las diferencias.
\end{abstract}

PALABRAS-CLAVE: Mujer, Género, Feminismo, Historia de las ideas, Filosofía

\footnotetext{
${ }^{1}$ El primer título para nombrar la idea que este trabajo desarrolla fue "Huéspedes hostigadas en los "puros" productos de la razón y la praxis cognoscitiva de fines del siglo XIX y principios del siglo XX en latinoamericana". En el transcurso de su escritura advertí que ese enunciado ya no me nombraba; había sido formulado desde el discurso androcéntrico que a veces se filtra por mi boca. Debí, claro está, cambiar el centro. Me apropié entonces de dos categorías. Una "contrabandistas" de la poetisa y ensayista Rosario Castellanos (México, Tel Aviv, 1925-1974) con la que nombra a mujeres excepcionales que "se separaron del resto del rebaño e invadieron un terreno prohibido", el de una cultura androcéntrica que poca atracción ejerce sobre lo femenino. Otra, "testigos sospechosos", la tomo de Victoria Ocampo (Argentina 1890-1979). Y, finalmente, "autómatas parlantes" es una construcción conceptual que designa a mujeres que han logrado acceder a la ciencia así como a la policía, a la religión, a la docencia, por tomar herramientas, patrones, constructos, estrategias, tradicionales sin hacer con ellas un uso crítico contra-hegemónico. Se trata de mujeres que sostienen el discurso que habla sobre ellas y por ellas. La presencia de estas mujeres en la historia no sólo insiste en integrarlas a la par del hombre como complemento o en tanto "iguales" al amo sino además en excluirlas de una creativa participación en la construcción colectiva y en la legitimación de herramientas propias de conocimiento, esto es, de la habilitación como sujetos capaces de intervenir en la producción, aplicación y circulación del conocimiento y por tanto en autonombrarse como un paradigma autónomo.
}

\footnotetext{
${ }^{2}$ Mariana Alvarado es Profesora de Grado Universitario en Filosofía (FFyL, UNCuyo), Especialista en Constructivismo y Educación (FLACSO), Diplomada en Cultura y Comunicación, (FCPyS, UNCuyo). Doctoranda por la UNCuyo. Becaria de CCT con lugar de trabajo en el Instituto de Filosofía Argentina y Americana, UNCuyo. Miembro del Centro de Investigaciones Interdisciplinarias de Filosofía en la Escuela (CIIFE), UNCuyo. Su área de investigación gira en torno a los vínculos entre historia de las ideas y filosofía práctica y se sitúa en los discursos pedagógicos de fines del siglo XIX y principios del siglo XX en la República Argentina. Tiene trabajos publicados como capítulos de libros y en revistas especializadas, entre ellos: "Educación Alternativa" en: Hugo Biagini y Arturo, A. Roig (dir.) Diccionario del pensamiento alternativo, tomo II, 2009. En línea en: http://www.cecies.org/articulo.asp?id=235. marianaalvarado@yahoo.com
} 
RESUMO: No que diz respeito "ao silêncio feminino" ao que Nuria Pérez de Lara (2009) alude para pensar "a construção da identidade do ponto de vista da diferença sexual", na relação entre as mulheres e a produção do conhecimento, neste trabalho se visibiliza o problema criado pelo androcentrismo na história do pensamento filosófico latino-americano do fim do século XIX e dos princípios do XX. Faz-se eco do protagonismo filosófico das mulheres na América Latina. A tempo para propor perspectivas para pensar uma outra filosofia, da experiência de ser mulher - de ser uma entre uns y outras diferentes a uma - que se articula com uma política do olhar feminino que teça uma história das ideias femininas latinoamericanas capaz de parir éticas da alteridade e pedagogias das diferenças.

PALAVRAS-CHAVE: Mulher, Gênero, Feminismo, História das ideias, Filosofia.

\section{El monólogo androcéntrico}

"Pero el silencio es cierto. Por eso escribo.

Estoy sola y escribo.

No, no estoy sola. Hay alguien aquí que tiembla."

(Alejandra PIZARNIK, 1981)

A mediados del siglo XX, la ensayista argentina Victoria Ocampo sostenía que la mujer era tema sobre el que se producía habla aunque eran los hombres quienes sostenían ese discurso. Desde la gratitud o el despecho, desde el ensueño o la decepción, desde el entusiasmo o la amargura, desde el aprecio o el resentimiento, el discurso androcéntrico se instalaba, a su juicio, por necesidad de resarcimiento. Los "testigos de la mujer" que han hablado por ella y de ella resultan ser "testigos sospechosos" en tanto sostenían/en declaraciones tendenciosas (OCAMPO, 1935, p 36).

Las mujeres, apenas hemos pronunciado palabras. Algunas hemos reproducido lo que otros dicen de nosotras. Más aún, algunas hemos creído tales palabras en tanto que otras han querido/debido creerles. Es a nosotras a quienes nos toca no sólo descubrir la geografía inexplorada que nuestro cuerpo sexuado representa en su plena diferencia sino además, pensar y hablar críticamente, a su vez, del hombre, en calidad de "testigo sospechoso" y de nosotras en tanto "autómatas parlantes". 
Dicha toma de conciencia no puede aparejar otra cosa que la de renunciar a sostener la continuidad del monólogo androcéntrico y la de denunciar la condición genérica de los "testigos sospechosos" y de las "autómatas parlantes".

Reconocimiento y denuncia que en la ensayística filosófica latinoamericana contribuiría a interrumpir ese monólogo vejatorio e injusto ${ }^{3}$ introduciendo una pausa en el discurso masculino sobre/para la mujer. Una pausa que no es el silenciamiento de voces masculinas. Un paréntesis que no quiere la desaparición de nombres de varones. Una discontinuidad para instalar en la continuidad la desnaturalización de la cristalización de la diferencia como inferioridad, discapacidad, incapacidad, ignorancia e incorregibilidad. Una pausa, un paréntesis, una discontinuidad que permita el retorno de algunos momentos de ese monólogo. Retorno en el que podamos pensar-nos en los testimonios de esos "testigos sospechosos" que tanto han hablado de nosotras y confrontar así el monólogo masculino con sus propios ecos en las "autómatas parlantes".

No se trataría, entonces, de hablar "de" la mujer ni tampoco "por" ella sino más bien de instalar la sospecha respecto del modo en el que se ha hablado de, por y para nosotras. Dar lugar a una mirada femenina sobre aquellos discursos que han hablado masculinamente de nosotras para hacer que el monólogo masculino y todos sus ecos se escuchen a sí mismos. Inaugurar, así, una historia en la que no se hable de nosotras y para nosotras. Otra historia en la que las mujeres narremos nuestras propias experiencias de hacer y ser féminas desde la que se gesten éticas de la alteridad y pedagogías de las diferencias.

\section{De ausencias, silencios y afasías}

"La" filosofía ha sido tradicionalmente pensada como una "profesión" propiamente masculina. En general su práctica ha sido atribuida a varones. Una historia de la filosofía, claro está, occidental, coloca a todos los presocráticos y los

\footnotetext{
${ }^{3}$ Valgan como ejemplo de discursos vejatorios aquellos que en Latinoamérica circularon en la segunda mitad del siglo XIX y en las primeras décadas del XX y que siguiendo las pautas desarrolladas por Augusto Comte (1798-1857) ubican a la mujer en el ámbito privado del hogar y de los augustos deberes de la reproducción humana y a la educación en su conciencia de ser madre y doméstica expulsándola de la vida pública y de la actividad científica y/o filosófica. En Chile, Juan Enrique Lagarrigue (1852-1927), en Argentina, Domingo F. Sarmiento (1811-1888) y José
} 
pitagóricos, a Sócrates, Platón y Aristóteles como representantes del pensamiento griego y antiguo, algunos santos como Agustín, Anselmo, Buenaventura o Tomás aparecen en el medioevo, Kepler, Galileo y Newton inauguran con la física una modernidad que aparece en los nombres de René Descartes, David Hume, Immanuel Kant. Una historia de varones o la masculinización de "la" historia de "la" filosofía. Podríamos hacer algunas disquisiciones y desde un pensamiento crítico, señalar la lógica de la "mismidad" sostenida en el pensamiento filosófico occidental -cuya máxima expresión la tuvo Hegel- e instalar desde una lógica de la diferencias otras posibilidades para otra historia que podría iniciarse con Heráclito para llegar a Maurice Merleu-Ponty atravesando a los filósofos de la sospecha Friedrich Nietzsche, Sigmund Freud y Karl Marx- como críticos de la racionalidad moderna o a la Escuela de Frankfurt, crítica de la racionalidad instrumental, -con un Herbert Marcuse o un Max Horkheimer- y dar rienda suelta con Michel Foucault. Aún así, desde una u otra lógica, desde una u otra historia -la de la mismidad, la de la diferencia- occidente ha instalado en "la" historia de "la" filosofía una mirada androcéntrica que sitúa y legitima la producción del discurso filosófico en las manos de los varones.

Estaríamos autorizadas a señalar en esa historia de varones contada por varones una ausencia que tiene ecos en otras historias. La historia de las ideas en Argentina y en América también se cuenta con rostros masculinos. En la filosofía latinoamericana el anonimato padecido por las mujeres implica ausencias y olvidos así como marginaciones. Se trata, en todo caso de una mala y ofensiva presencia. La mujer ha estado presente como tema y problema para y de los hombres pero la cuestión está en pensar por qué las que estuvieron en aquellos tiempos no han sido nombradas; qué sutiles estrategias no han permitido la emergencia visible de una latinoamericana pensante; quién se arrogó el derecho de no nombrarla y en ello negarle pensamiento en su capacidad de filosofar; qué tipo de relaciones entre el saber y el género se gestaron/an a la hora de construir pensamientos en la academia; qué extraños vínculos se pueden establecer entre esas filosofías, entre esas historias y nosotras, las mujeres. ¿Qué historia podría nombrarnos? ¿Qué "favor" de la mujer una desigualdad biológica a resolver, a corregir. 
filosofía contendría nuestros rostros, y cómo se vincularía con nuestros cuerpos? ¿Qué estrategias heurísticas y qué herramientas epistemológicas estaríamos dispuestas a construir y legitimar para narrarnos?

Ausencias porque la mujer no ha sido tema ni problema de reflexión para las mujeres sino a través del discurso androcéntrico sostenido por los "testigos sospechosos" y reproducidos por las "autómatas parlantes". Silencios porque las mujeres hemos pensado y lo pensado no ha sido escuchado. Afasia porque la mujer no ha podido decir de sí desde sí, hasta que nombró su diferencia. Ausencias porque al hablar de nosotras no lo hacemos entre/con nosotras sino para nosotras y, aún, sosteniendo el discurso androcéntrico en los hábitos, las costumbres, los usos que atraviesan no sólo la academia sino también la escuela, la casa, la cama. Ausencia porque para sostener "nuestro" discurso apelamos a pensadores varones, porque para legitimar nuestra palabra nos afirmamos en el habla masculina que nos desnombra. Es la mujer pensadora, la filósofa quien para legitimarse no ha podido más que sostener-se desde el discurso androcéntrico sin reconocer a sus pares, sin legitimar a mujeres que bien pueden autorizar su discurso. Afasia porque al hablar de temas "propiamente" filosóficos no pronuncia temas "propiamente" femeninos o, de otro modo, porque los temas que se ha dado la filosofía para pensar, no son los temas a los que las féminas le han puesto palabra. Silencios porque las herramientas utilizadas por las mujeres pensantes no son las herramientas legitimadas por el método científico androcéntrico. Tanto así, que la mujer ha sido negada en su capacidad de autointerpretación, de creación y de expresión autónoma del logos filosófico.

Este proceso de masculinización de la filosofía y de una filosofía masculinizante instala una relación unidireccional entre la filosofía y la mujer en la que se le asigna un lugar mudo, más aún, un lugar mudo en el mundo masculino que habla por ella y que la perfila como lo otro que está y queda fuera del mundo racional-teórico de la filosofía. Un mundo en el que no tienen lugar las emociones, los sentimientos, la pasión, el amor, la intuición, el cuerpo. Al parecer el himen no sólo es un obstáculo epistemológico. 
Esta ausencia, este silencio, esta afasia, esta negación es una consecuencia de un proceso mucho más amplio -en tanto que se estructura análogamente a los procesos culturales unilateralmente masculinos por los que atraviesan los países latinoamericanos- que no es otro que la estructuración sexista de la cultura iberoamericana en sus dinámicas de desarrollo teórico y de institucionalización socio-profesional en general.

Una cultura que ha normalizado la negación sistemática del protagonismo femenino. Así los textos han reseñado, compilado, editado, publicado textos fundamentales del pensamiento latinoamericano sin que en ellas se hayan recogido nombres, rostros o voces femeninas. Se trata en palabras de Raúl FornetBetancourt (2009) de la normalización de una anomalía en una cultura que en la República Argentina se propagaba bajo la impronta del positivismo en un momento decisivo como fue el de la reorganización nacional y republicana en el siglo XIX.

En la segunda mitad del siglo XIX la República Argentina contó con tendencias filosóficas de corte romántico que pudieron extender su alcance, intensidad e influencia hasta entradas tres décadas en el siglo XX. Tanto el eclecticismo de cátedra, el racionalismo, como el krausismo y las diversas formas del positivismo fueron tendencias que acusaron vínculos con el espiritualismo de mediados del siglo XIX y principios del siglo XX en la República Argentina. La emergencia del movimiento feminista ${ }^{4}$ moderno coincidió con los esfuerzos por

\footnotetext{
${ }^{4}$ Francesca Gargallo piensa al feminismo como una corriente política de la que si bien pueden rastrearse antecedentes en escritos del medio evo y del renacimiento nace moderna y cruza la historia contemporánea desde la Revolución Francesa en 1789 hasta la actualidad. Desde la Declaración de los Derechos de la Mujer y de la ciudadana (1791) de Olympe de Rouge hasta principios del siglo XX, las mujeres de Europa, de América anglosajona y latina y de Oceanía libraron combates para lograr igualdad jurídica, política y económica con el hombre. Una conciencia femenina atenta a su propia historia capaz de una memoria colectiva emerge entre siglos como intérprete de sí misa. El protagonismo de la mujer ahora como intelectual se instala en su propio relato como algo que hay que defender porque es la mujer la que se autoafirma como protagonista del relato de la historia que la reversión de la historia del pensamiento latinoamericano pero ahora desde la mirada femenina cuya primera forma se articula en el reclamo por el reconocimiento de que la historia intelectual latinoamericana fue obra de mujeres para luego sostener la producción de un pensamiento explícitamente femenino. Este proceso histórico cultural de autoafirmación femenina pudo consolidarse como movimiento feminista filosófico agente de una transformación en el vínculo entre mujer y saber, mujer y pensamiento, mujer y producción del conocimiento, mujer y filosofía. Se trata, por tanto, para Francesca Gargallo de la reivindicación incondicional del derecho de la mujer no solamente a "ingresar" al mundo (masculino) de la filosofía (del que se la había excluido) sino también a decir en forma femenina qué es la filosofía.
} 
articular un modo propio de hacer filosofía en América. (ROIG, 1972, p 7-8). La tendencia a profesionalizar la filosofía como una tarea que exige esfuerzo, aprendizaje y continuidad cobró fuerza en las primeras décadas del XX en la Argentina. Un filosofar "riguroso" que en términos de Francisco Romero estuvo en manos de los "fundadores" de la filosofía, de los "creadores de tradiciones", de los "patriarcas" como los iniciadores de un proceso de reestructuración filosófica. La creación de la Facultad de Filosofía en 1896 en Buenos Aires; la presencia de intelectuales de prestigio en sus cátedras y el ejercicio de su magisterio; la inclinación por la actualización filosófica y la exigencia de ponerse al día con la filosofía europea; la creación de órganos de publicación, las publicaciones en orden a las distintas disciplinas filosóficas y los nuevos lineamientos de circulación fueron algunos de los mecanismos que evidenciaron esta disposición.

Romero entiende que este proceso que caracteriza a toda Iberoamérica tuvo lugar en Argentina en la Universidad de Buenos Aires donde comenzaron a circular las primeras posiciones críticas frente al positivismo. Este acontecimiento que tendría un lugar tan decisivo para el destino de la filosofía habría sido obra de los "patriarcas" una labor única y exclusivamente masculina, por tanto, sin la participación de la mujer, o más bien, en todo caso, sin el reconocimiento de ningún nombre femenino.

En la generación de los fundadores se encuentran las figuras de Antonio Caso (1883-1946), Alejandro Deustua (1849-1945), Enrique José Varona (18491933), José Vasconcelos (1882-1959), Carlos Vaz Ferreira (1872-1958), Raimundo Farias Brito (1862-1917). José Ingenieros y Alejandro Korn (1860-1936) fueron quienes sostuvieron, en Argentina, el convencimiento de emprender el estudio filosófico sistemático, serio y autónomo, en lo que podría denominarse los orígenes nuestra historiografía filosófica argentina. Una convicción que colocó a la tarea filosófica en un academicismo despolitizado asignándole un lugar a la filosofía ajeno a las condiciones socio-culturales en el marco de las cuales se gesta todo saber y privilegiando su reproducción en el ámbito universitario. Una valoración que desconoce la presencia de las voces, reflexiones, debates y prácticas femeninas y señala su ausencia en los procesos de producción, de circulación así como de 
institucionalización de la investigación filosófica. Un olvido que ha instalado la ausencia femenina como parte de la normalidad que alcanzó la profesionalización filosófica más aún, fundando la profesionalización filosófica en la ausencia normalizada de la mujer en los países iberoamericanos ${ }^{5}$.

\section{Otros rostros, otras voces, otros nombres, otras}

"Quiero existir más allá de mí misma: con los aparecidos. Quiero existir como lo que soy: una idea fija. Quiero ladrar, no alabar el silencio del espacio al que se nace." (Alejandra PIZARNIK, 1981, p 231)

La historia de la construcción del conocimiento y de la praxis cognitiva puede ser contada con nombres femeninos que en algunos casos acompañaron y en otros precedieron los procesos reivindicativos feministas. El desarrollo de la conciencia intelectual americana tuvo protagonistas femeninas que bien pueden alimentar una historia capaz de atravesar la topología masculinizante. Entre ellos cuentan los rostros y las voces de Juana de Asbaje y Ramírez de Santillana o bien Sor Juana Inés de la Cruz (1648-1695) con su Carta a Sor Filotea de la Cruz de 1691; la franco-peruana fundadora del feminismo moderno Flora Tristán (18031844); la poetisa y escritora cubana Gertrudis Gómez de Avellaneda (1814-1873); las escritoras peruanas Clorinda Matto de Turner (1852-1909) y Margarita

\footnotetext{
${ }^{5}$ Esta situación que supone un olvido y una valoración respecto de "lo femenino" y del lugar de los cuerpos, de las voces, de los rostros femeninos en la producción discursiva filosófica se extiende en la periodización de la filosofía iberoamericana en el siglo XX propuesta por Francisco Miró Quesada (MIRÓ QUESADA, F. 1974, 11 y ss.). En la "generación de los forjadores", la que sigue inmediatamente a los "patriarcas" la filosofía es un asunto de varones. Al parecer de Quesada y de Romero ninguna mujer tuvo lugar entre los que "fundan" y "forjan" la filosofía latinoamericana con perfil propio. Más aún quienes inician su labor creativa entre 1940 y 1950, la tercera generación entre quienes cuentan Arturo Ardao (1912-2000), el mismo Quesada (1918), Arturo Andrés Roig (1922), Luis Villoro (1922) y Leopoldo Zea (1912-2004)-, es netamente masculina con el agravante de que la mujer no sólo no ha sido tema filosófico a considerar (FORNET-BETANCOURT, 2009, 46 y ss.) sino que además no ha sido una interlocutora válida desde donde legitimar el discurso andrógeno. Una tendencia que bien puede considerarse en proceso de mutación si tenemos en cuenta los intercambios que han tenido lugar desde la década del '90 entre Horacio Cerutti Guldberg y las feministas Ofelia Schutte, Graciela Hierro, Aralia López, Eli Bartra y Francesca Gargallo, así como las interlocuciones desde Poulain de la Barre con las Preciosas, hasta Arturo Andrés Roig y Horacio Cerutti con las feministas latinoamericanas en los tiempos que corren (GARGALLO, Francesca, 2004, 24 y ss.).
} 
Práxedes Muñoz (1848-1904) así como la geógrafa e historiadora, también peruana, Teresa González de Fanning (1835-1918), la argentina Josefina Pelliza de Sagasti (1844-1932) o la colombiana Soledad Acosta de Samper (1833-1913) o la puertorriqueña Luisa Capetillo (1875-1922).

Otras mujeres se han destacado en el desarrollo del feminismo filosófico en América Latina como Teresita de Barbieri, Lorenia Parada, Beatriz Schmukler, María Luisa Femenías, Montserrat Sagot, Sara Poggio, Graciela Hierro Perezcasto, Sara Beatriz Guardia, Ofelia Schutte, Alejandra Ciriza Jofré y Marta Lamas quienes en la actualidad han escrito fundamentalmente en Costa Rica, México, Perú, Cuba y Argentina honestamente interesadas en complejizar las categorías de análisis de la situación de las mujeres. Claro está que estas "contrabandistas" no hubiesen surgido sin la labor de otras excepcionales mujeres que sin formar parte del movimiento feminista filosófico han sido parte de la posibilidad de transformar nuestra experiencia femenina con la filosofía dentro y fuera de la academia, entre ellas registramos algunos nombres entre otros muchos con las que ya van tres generaciones de filósofas: las argentinas Dina V. Picotti, Lusía Piossek Prebisch, Adriana María Arpini, Celina Ana Lértora Mendoza y Clara Jalif de Bertranou, las mexicanas Fernanda Navarro y Elsa Cecilia Frost, la cubana Isabel Monal Rodríguez, las brasileras Neusa Vaz e Silvay y Cecilia María Pinto Pires.

Cabe, tal vez preguntar si es deseable que estas mujeres formen parte de una historia de la filosofía latinoamericana, si el hecho de hacerlas visibles basta para reconocer en esa historia un lugar en cuanto fundadoras-forjadoras de un filosofar propiamente latinoamericano que ahora resignificado desde los rostros femeninos instale en las voces de las féminas un modo propio de hacer filosofía.

Tal vez la cuestión sea más interesante si atendemos a cómo hicieron para contrabandear sus ideas, es decir, cómo a pesar de la vigilancia epistemológica que las expulsó de la historia occidental, de la historia iberoamericana, de la historia americana y de la argentina, pudieron instalar sus producciones. Más aún qué fue lo que las impulsó a arriesgarse como contrabandistas que disolvieron los límites disciplinares al tejer femeninamente filosofía y literatura, pensamiento $y$ experiencia, manos y arcilla. 
Valen a modo de ojal las ideas feministas en la poesía de Enriqueta Ochoa o en la narrativa de Marvel Moreno así como las intervenciones y performance que desde las artes plásticas desafían, provocan y movilizan con rituales de intervención reacciones que hacen estallar los conceptos de belleza y neutralidad en la producción artística en la frontera entre lo culto y lo callejero, entre lo tecnológico, el plástico y el cartón. Entre las performanceras de principios del siglo XXI, a Lorena Wollfer, Pilar Villela o su transmutación en la Llorona, Lorena Orozco, Andrea Ferreira encarnada en Chuchita la boxeadora, Katia Tirado, los reportes de Mónica Mayer sobre las creaciones de Elvira Santamaría, Laura García, Katnira Bello y las artes visuales a través de las producciones de Minerva Cuevas.

\section{Asimilación/integración}

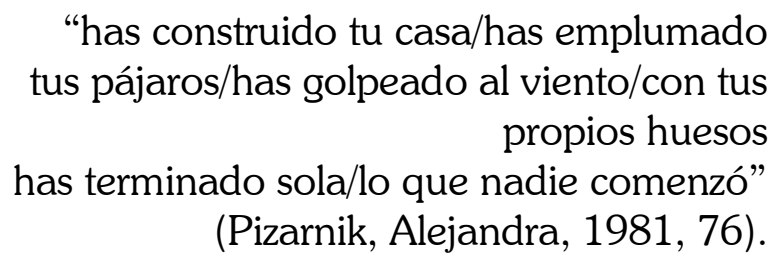

Dirigir la mirada hacia nombres, rostros, voces de las mujeres parias de una historia de la filosofía, más aún, de los procesos de construcción, circulación y aplicación del conocimiento científico-filosófico nos coloca ante la posibilidad de crear otra relación con las miradas de "las contrabandistas" que modifican la relación de las mujeres con la filosofía, con la historia, con nosotras mismas.

Sostener una relación de alteridad entre las miradas de aquellas mujeres y la nuestra en los tiempos que corren requeriría no sólo de una imperiosa profundización en las transformaciones operadas en la filosofía desde las mujeres que modificaron radicalmente los procesos de producción, aplicación, circulación y legitimación del conocimiento sino además modificaciones en de los hábitos en el uso de la razón que no pueden sino estar impulsadas por reformas radicales en las prácticas escolares.

La posibilidad de una historia de las ideas filosóficas feministas supone no sólo el reconocimiento de la historicidad de las ideas feministas y de su incidencia 
conservadora o revolucionaria en un ámbito cultural mayoritariamente occidentalizado sino además la idea de que el feminismo habría de situarse como una praxis política y una ética de la alteridad, tanto en su etapa emancipadora cuando las mujeres piden ingresar en condiciones de igualdad en la historia del hombre, como en su etapa de liberación y reivindicación de la diferencia, cuando las mujeres cuestionan y se separan del modelo masculino sostenido como universalmente válido.

Todo lo cual nos coloca frente al desafío de re-fundar la filosofía en tanto que cualquier programa de compensación o de complementación, cualquier estrategia de integración llevaría a instalar las miradas femeninas en "el" modelo masculino de hacer historia, de hacer ciencia, de hacer filosofía cómplice de los prejuicios sexistas reproductores de una cultura patriarcal, todo lo cual derivaría en prácticas colonizantes de asimilación o subsunción de la diferencia.

Entonces, sería deseable/necesario/esperable una re-fundación de la filosofía en la que no alcance con revisar la historia para incluir amordazadas, mutiladas o violentadas a mujeres filósofas; en la que no baste con ampliar la historia de la filosofía para dar entrada a las contrabandistas - en diálogo con las autómatas parlantes y a los ecos de los testigos sospechosos-, en la que la filosofía a la que nos "incorporamos" las mujeres ya no sea la configurada alrededor del uso varonil de un filosofar cuyas prácticas de producción, circulación y aplicación del conocimiento sostienen su legitimidad en los circuitos institucionales/académicos.

Quizás se trataría de una calificación de la mirada femenina, desde nuestra realidad sexuada; de una afirmación de nuestro específico estar en el mundo y por tanto diferente las unas de las otras y de los otros; de una toma de conciencia que nos constituye en la diferencia de "un entre" ser mujeres entre sí en el que existe la posibilidad de crear otros modos de vincularnos con la filosofía y la historia modos que tejen éticas de la alteridad y pedagogías de las diferencias en el marco de las cuales sea posible pensar otra educación y hacer otra escuela.

Parir filosofías a nuestra manera, desde nuestras memorias, a partir de nuestras experiencias de ser mujer que en tanto filosofar se relacionen con otras filosofías, que en tanto emergentes históricos se vinculen con otras historias. La 
voz, el rostro, la mirada de las mujeres en el nombre de esta mujer históricamente situada en órdenes simbólicos que pueden/deben ser reelaborados en la práctica de un "entre" de relaciones con mujeres.

No puedo más que arrojar algunas preguntas para situar el planteo precedente en ámbitos propiamente escolares con la mera inquietud de repensar las prácticas áulicas. En principio chay lugar en la escuela para la construcción un conocimiento situado atento no sólo a los discursos sino también a las prácticas? ¿Cómo se articula esa construcción entre niños y niñas? ¿Qué cabida tienen los discursos femeninos latinoamericanos en esa construcción? ¿En qué medida la mirada docente está atenta al os discursos sobre, de y por la mujer que circulan entre los más pequeños? ¿Qué lugar ocupa la institución educativa respecto de la circulación de discursos andrógenos? ¿Es la escuela el lugar para instalar la sospecha respecto del modo en el que se ha hablado de, por y para nosotras? ¿Es en la academia donde habría de tener lugar la mirada femenina sobre aquellos discursos que han hablado masculinamente de nosotras? ¿Cuáles son los espacios para pensar lo que se dice por y sobre nosotras y cuáles los lugares en los que dialogamos respecto de lo que cada una de nosotras sostiene sobre nosotras? ¿Será que lo femenino nada tiene que ver con lo escolar, con los usos y las costumbres, con el modo en el que abordamos los textos, con la disposición a sabernos sujetos activos en la historia? ¿Serán las más pequeñas las que habrán de inaugurar una infancia latinoamericana para una historia femenina? ¿Será en la escuela donde esa infancia comienza a gestarse?

\section{BIBLIOGRAFÍA}

CAREAGA PÉREZ, Gloria. Feminismos Latinoamericanos: retos y perspectivas México: Universitario de Estudios de Género (PUEG), 2002.

CIRIZA, Alejandra y Virginia FERNANDEZ (1993) "La mujeres y su inclusión en las prácticas políticas", en: Argentina del 80 al 80, Arturo Andrés Roig (comp.), México, UNAM, 1993.

Apuntes para una crítica feminista de los atolladeros del género en: Estudios de Filosofía e Historia de las Ideas. Revista Anual de Historiografía e Historia 
de las Ideas. Mendoza, INCIHUSA, 2007, año 8, nº 9, 23-41. En línea en: www.estudiosdefilosofia.com.ar

FORNET-BETANCOURT, Raúl. Mujer y filosofía en el pensamiento iberoamericano. Momentos de una relación difícil. Barcelona: Anthropos, 2009.

FRIGERIO, Graciela. Contra lo inexorable en Ciudadanos s/l, s/e, 2004.

GARGALLO, Francesca. Ideas Feministas Latinoamericanas. México: Universidad de la Ciudad de México, 2004.

OCAMPO, Victoria. "La mujer y su expresión" en Sur 11. Buenos Aires: 1935.

PEREZ DE LARA, Nuria. Pedagogía de las diferencias. Buenos Aires: FLACSO, 2009.

. De la primera diferencia a las diferencias. Buenos Aires: FLACSO, 2008.

PIZARNIK, Alejandra. Obras Completas. Poesía y prosa. Buenos Aires: Corregidor, 1981.

ROIG, Arturo. Cuestiones de dialéctica y de género en Krause. Sofía o la nueva mujer. Estudios de Filosofía e Historia de las Ideas. Revista Anual de Historiografía e Historia de las Ideas. Mendoza, INCIHUSA: 2007, año 8, ${ }^{\circ}$ 9, 57-72. www.estudiosdefilosofia.com.ar

. El espiritualismo Argentino, Cajica, 1972, 7-8.

ROMERO, F. Sobre la filosofía en América. Buenos Aires: Editorial Raigal, 1952.

SKLIAR, Carlos s/a Discursos y prácticas sobre la deficiencia y la normalidad. Las exclusiones del lenguaje, del cuerpo y la mente. Programa de Posgraduación en Educación, Núcleo de Investigaciones en Políticas Educativas para Sordos. Brasil: Universidad Federal de Rio Grande do Sul. 